\title{
Job quality trajectories among baby-boomers in Germany and their consequences for the motivation to work - results from the lidA cohort study
}

\author{
Michael Stiller* (D), Nina Garthe (D) and Hans Martin Hasselhorn (D) \\ Department of Occupational Health Science, University of Wuppertal, Wuppertal, Germany \\ ${ }^{*}$ Corresponding author. Email: mstiller@uni-wuppertal.de
}

(Accepted 13 August 2021)

\begin{abstract}
In light of a large proportion of older workers leaving the German labour market in the near future, policy makers aim to extend working lives to ensure sustainability of the social security system. In this context, safe and healthy working conditions are considered a precondition for encouraging employment participation. To understand better the role of the work environment in pre-retirement years, we draw upon an established model of five job quality profiles for the German ageing workforce. We explored seven-year profile development and linked selected manual and non-manual job quality trajectories to the motivation to work (MTW) using data from the 2011, 2014 and 2018 assessments of the lidA cohort study (valid $\mathrm{N}=2,863$ ). We found that older workers shifted to physically lessdemanding profiles. Individual profile stability was prevalent among one-third of the workers. In 2018, there was a higher MTW when job quality remained favourable or improved early, while later improvements were associated with lower MTW. Early deterioration of job quality was associated with lower MTW levels among workers with non-manual trajectories only. The results highlight the dynamic job quality situation of the older German workforce and the importance of adopting a person-centred perspective when investigating working conditions and its effects. They further underline the need to consider quality of work when designing and implementing strategies to extend working lives.
\end{abstract}

Keywords: accumulation; working conditions; older worker; prospective cohort study; extended working lives; social inequality; retirement; motivation to work

\section{Background}

Accelerated population ageing and its economic dynamics are major challenges as they put pressure on the national pension and social security systems of almost all Western countries (Börsch-Supan et al., 2003). According to the Organisation for 
Economic Co-operation and Development (OECD), the number of individuals in Germany aged $65+$ per 100 people of working age (20-64 years) is expected to increase from 36.5 in 2020 to 58.1 in 2050. It is estimated that it will become stable at around 60.0 by 2080 (OECD, 2019: 175). This is the seventh highest projected old-age to working-age ratio among the European Union (EU) countries. To attenuate the fiscal consequences of an ageing workforce, particularly in the next years, German policy makers aim to extend working lives (EWL), e.g. by raising employment participation among underrepresented social groups such as women, migrants or those of older working age, and by raising the statutory retirement age for all employees (Federal Ministry for Economic Affairs and Energy, 2016: 37). Although employment rates among older workers in Germany have increased substantially between 2009 and 2019 (age group 55-59: from 69.9\% to 81.8\%; age group 60-64: from $38.6 \%$ to $61.8 \%$; Federal Office of Statistics, 2020), German policy regards continued promotion of sustainable working conditions necessary to improve health and well-being in the workforce with the aim to enhance employability in later working life (Federal Ministry for Economic Affairs and Energy, 2016: 37).

The multiple repercussions of an ageing workforce approaching retirement age have gained increasing academic attention over the last two decades and involve many research lines in its investigation (e.g. Börsch-Supan et al., 2003; Radl, 2012; Hofäcker, 2015; Hofäcker and Naumann, 2015; Dauth and Toomet, 2016; Klaus et al., 2017; Franke and Simonson, 2018; Hasselhorn and Ebener, 2018). Empirical evidence on the impact of working conditions on later employee health and well-being and - consecutively - employment, is increasing (e.g. Dragano and Schneider, 2011; van Aerden et al., 2015; European Foundation for the Improvement of Living and Working Conditions (Eurofound), 2016; Fisher et al., 2016; Knardahl et al., 2017; Bujacz et al., 2018; Ní Léime et al., 2020). In a systematic review of 20 longitudinal, international studies, Scharn et al. (2018) identified 21 single work factors that affect retirement timing, suggesting that the work domain may be of substantial importance in the context of EWL research. Furthermore, a systematic review of 20 European studies, published from 1996 to 2010, identified a higher risk for disability retirement associated with psychosocial job demand exposure (Dragano and Schneider, 2011). The associated characteristics in this context were low control, monotonous work tasks, work stress, lack of social support, work organisational and leadership behaviour problems. The adverse impact of low control for disability retirement was especially verified in a recent systematic review and meta-analysis on 39 mainly Scandinavian studies from 2002 to 2014, with over 200,000 employees covering all working ages or higher working-age groups only (Knardahl et al., 2017). The authors also found limited evidence for a higher risk of disability retirement associated with organisational change, lack of employee development, monotonous work task and effortreward imbalance. To summarise, these findings suggest impaired employability and premature retirement when adverse physical, psychosocial and work organisational work exposures cumulate in later working life. They also highlight the need for the consideration of the entirety of the work environment when aiming to extend working lives. Current EWL policy is considering later retirement as a realistic objective for all employees. However, it has been criticised widely for 
disregarding the need for implementing measures to improve job quality as a precondition for achieving this political goal (Hasselhorn, 2020a).

Taylor et al. (2016) add the notion that different motivations in the heterogeneous older workforce should also be recognised in research, in order to understand better the complex work-retirement transition. Despite the prevailing EWL agenda and increasing proportions of employees who are about to transition to retirement (Federal Office of Statistics, 2020), the willingness to continue working among them in Germany continues to be low (Hofäcker, 2015), widely follows the social gradient (Hofäcker and Naumann, 2015) and is clearly associated with various work exposures in the direction expected (Hasselhorn, 2020b).

When linking the motivation to bring forward or postpone retirement to working conditions, Fisher et al. (2016) recommend that research should not limit its focus on single work exposures, but rather take the multiple facets of job quality and their interplay into account. Thus, the central aim of this study is to investigate whether and how the entirety of job quality in the older workforce in Germany changes in the years approaching retirement age, and whether and how these changes impact the motivation to work.

\section{Typologies of job quality}

Occupational epidemiology has begun to move from investigating single job quality characteristics to considering a multitude of them simultaneously using finite mixture modelling. In doing so, the scientific focus lies on identifying typical constellations of work exposures that comprehensively capture the work situation of certain groups of employees (Lowe, 2007; Vanroelen et al., 2010; Eurofound, 2016). The EU agency Eurofound identified five job quality profiles with seven established indices by means of latent profile analysis (LPA), using cross-sectional data of roughly 27,000 workers from the $28 \mathrm{EU}$ states covering the full range of working age (Eurofound, 2016). Their least favourable manual profile scored adversely on almost all job characteristics and, consequently, workers assigned to this profile may constitute a potential risk group for impaired health, wellbeing, and early exit from work and employment. In contrast, identification of a most favourable profile was not as clear-cut, as the remaining profiles scored favourable on some characteristics (e.g. in the physical domain), but adverse on others. Similar research attempts were already undertaken for Canada (Lowe, 2007) and Belgium (Vanroelen et al., 2010). While such person-centred approaches better portray the heterogeneity of the workforce by taking the exposure perspective of the worker into account, the temporal dimension as an integral feature of working life is not considered adequately (Dannefer, 2003; Baltes et al., 2012; Amick et al., 2016). This, however, is required by lifespan and accumulation theorists who emphasise the dynamic impact that work and employment may have for the individual's constitution over working life (Dannefer, 2003; Baltes et al., 2012). To overcome this limitation, Bujacz et al. (2018) empirically identified four latent classes of psychosocial working conditions by means of latent transition analysis among 1,700 Swedish high-skilled workers and investigated class stability over six years. In their study, workers from two classes scoring adversely on the chosen characteristics tended to shift to a less-demanding class regarding 
work intensity, while a class scoring favourably on all characteristics remained stable in size.

Besides a differentiated understanding of the relation between work quality and employment, clustering older employees as outlined above also facilitates the detection of inequalities in the work-retirement transition, because some job quality constellations may systematically disadvantage social groups (Dannefer, 2003). Today, there is growing academic concern that the EWL paradigm bears the risk of exacerbating social inequalities (Hasselhorn, 2020a; Ní Léime et al., 2020). For example, after large-scale implementation of EWL measures in Germany, the lower educated tended to work longer for financial reasons (Hofäcker and Naumann, 2015). In another study of 1,300 Swedish retirees, a higher retirement age was associated with worse post-retirement health for the lower but not the higher educated. This was even more pronounced when retiring involuntarily, due to increasing physical demands at work (König et al., 2019). These examples demonstrate systematic accumulation of adversities over the later lifecourse and warrant critical reconsideration of the EWL paradigm in the face of a poor-quality work environment (Dannefer, 2003; Phillipson, 2019). Accordingly, academics argue for improvement of job quality as a precondition for sustainable policies to encourage employment participation in later life with the best possible health (Phillipson, 2019). Current EWL strategies do not differentiate systematically between social groups differently equipped with resources and risks. This raises ethical concerns regarding the long-term consequences of EWL for disadvantaged workers (Hasselhorn, 2020a).

Until recently, there were no job quality profiles available for baby-boomer cohorts in Germany. However, different profile distributions between European countries (as found by Eurofound, 2016) suggest different profiles may emerge when specific age groups of the working population are investigated in single countries. This limitation was overcome by a recent study, in which the entirety of the work environment of German baby-boomer cohorts was described with different constellations of nine job quality characteristics (Hasselhorn et al., 2020b; see Figure 1).

Five profiles were identified by means of LPA for predominantly manual ('Poor Quality' (PQ), 'Relaxed Manual' (RM)) and non-manual workers ('Strained non-Manual' (SnM), 'Smooth Running' (SR), 'High Flying' (HF)), which build the conceptual base for the research questions addressed in the present study. Workers assigned to PQ score adversely on almost all characteristics, while those in RM build upon favourable work intensity and social resources. This difference between both profiles finds expression in the poorest physical and mental health and work ability, and the highest work-privacy conflict for PQ, while those in RM show better mental health and the lowest work-privacy conflict (Hasselhorn et al., 2020b). Importantly, the distribution of basic sociodemographic characteristics is quite similar for workers in PQ and RM: both have predominantly low to medium educational levels, as well as task complexity levels, and work frequently in agriculture, production, logistics and safety, and certain services. Workers in SnM experience a complementary job quality constellation to RM, while the constellation in SR may be the most resource-rich for assigned workers. The differences between these profiles are expressed by the poorest mental health and the highest work-privacy conflict for those in SnM, while workers in SR score favourably on 


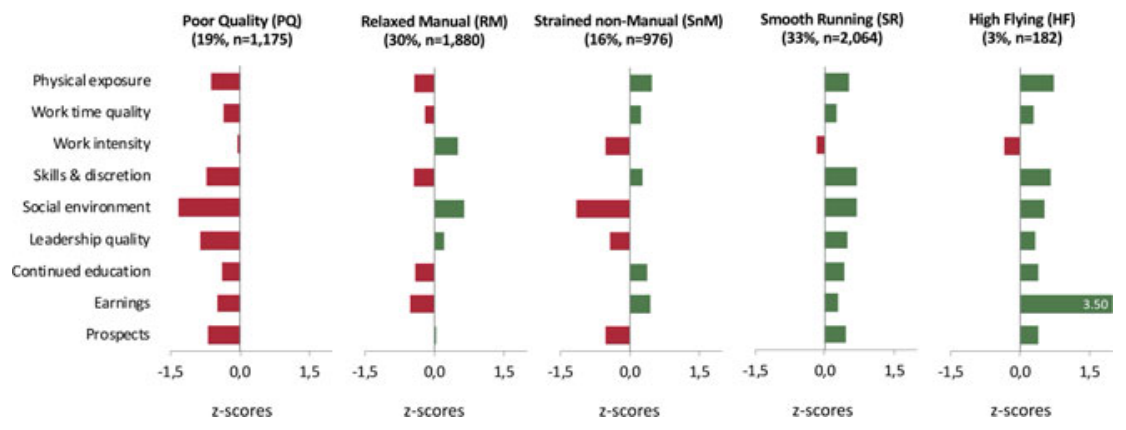

Figure 1. Job quality profiles for older workers in Germany.

Notes: $\mathrm{N}=6,277$. Red: adverse manifestation. Green: favourable manifestation. The earnings bar of the HF profile is shortened and the actual $z$-score is displayed.

Source: Adapted from Hasselhorn et al. (2020b).

the above-mentioned outcomes. Workers assigned to SnM and SR similarly display medium to high educational levels and cover the upper range of task complexity levels. Here, natural and information technology sciences, business organisation and administration, the health and social sector, and humanities are the most prevalent occupational areas. Consequently, and with respect to both manual and non-manual profiles, adversity (PQ, SnM) or favourability (RM, SR) of work exposure seems to depend on local working conditions rather than on sociodemographic characteristics. Finally, the very small HF profile is similar to SR but with extremely high earnings, which manifests in the best physical health and work ability (Hasselhorn et al., 2020b). To summarise, the PQ profile may represent an adverse job quality constellation among manual workers and RM the favourable counterpart. For non-manual workers, SnM reflects the adverse constellation and SR the favourable counterpart (HF may be considered as a special case of SR for ease of tangibility). Together, these five profiles portray specific job quality constellations with different consequences for health, motivation and employability. To date, it is unknown how the work environment of the baby-boomer workforce in Germany - as represented by these job quality profiles - develops in their final working years and what consequences change or stability of the work environment may have for the individual worker.

\section{Motivations in the retirement process}

Employment-related motivations are sparsely researched considering conceptual and methodological issues (Ebener, 2019), even though they are ascribed high relevance for the ageing workforce in retirement research (Wang and Shultz, 2010; Kooij et al., 2011; Hasselhorn et al., 2015). A recent advancement was made by the conceptual separation of a motivation to work (MTW) from a job-specific motivation at work and motivation to retire (Kanfer et al., 2013). While the latter two are assumed to target allocations of effort at work and exit from an existing work arrangement in later working life, respectively, MTW is considered a generic, purposive motivation to enter into a work arrangement and to participate in the 
workforce up to and beyond normative retirement age (Kanfer et al., 2013: 256). Regarding MTW as a new hypothetical construct, recent evidence from data representative for employed baby-boomers in Germany supports the assumption of MTW as a unique motivation in later working life (Ebener, 2019).

It is assumed that MTW gains salience in later working life (Kanfer et al., 2013) and that it may function as a personal resource in the work-retirement transition (Wang and Shultz, 2010; Kanfer et al., 2013). This allows the integration of the construct of motivation into broader concepts that focus on the investigation, understanding and prediction of outcomes of the retirement process. One such concept is the lidA framework on work, age, health and employment participation, where MTW (besides work ability) functions as an immediate determinant that mediates the association of retirement with antecedents from the work and private domains, health and (partly) finances (Hasselhorn and Ebener, 2018). Here, retirement is considered a process reflecting decades of work exposure affecting an individuals' MTW and their pathway towards (quality and timing of) retirement. Thus, specifically among workers approaching retirement age, the accumulated effect of job quality should be reflected by their MTW.

However, most research questions in this field are investigated in cross-section. One such study with approximately 230 German employees aged 54-62 showed that job demands were negatively related, and job resources positively related to MTW - with both effects being mediated through differences in the perception of work as coherent and concurrent health (Lichtenthaler and Fischbach, 2016). Conceptually similar results were found in the Netherlands for care workers aged 40-63 (Polat et al., 2017). In an exploratory cross-sectional study on nearly 2,000 older employees aged 55-74 in the Swedish health-care sector, Nilsson (2017) investigated three groups of employees: those who would like to and think they are able to work beyond 65 years, those stating they are able to but do not want to, and those negating in both instances (a corresponding fourth group was too small for analyses). Here, work environmental factors were consistently associated with the ability to work beyond retirement age and work motivational factors in turn discriminated most, regarding the desired retirement age. This suggests that different working conditions may affect representations of retirement on different levels (Nilsson, 2017).

Such studies yield important evidence on the association of working conditions and MTW in general, yet neglect the temporal dimension and, thus, accumulated exposure effects ( $c f$. Lowe, 2007; Vanroelen et al., 2010; Fisher et al., 2016; Hasselhorn et al., 2020b), a perspective that might be advised in research on the work-retirement transition (Baltes et al., 2012; Amick et al., 2016). Of the few studies that investigated this association longitudinally, Frins et al. (2016) found in a representative Dutch sample of 2,900 workers aged 50-64 that after a one-year follow-up, those with high job resources wanted to retire later, whereas this was reversed for those with high demands. Further, they found evidence for the presence of motivational gain and loss cycles, where availability of job resources enabled accumulation of more resources. Whereas high demands prevented effective coping, thus resulting in accumulation of more demands. Conceptually similar results were found by Schreurs et al. (2011) for Belgian workers aged 45+.

Despite this evidence for accumulation effects of adverse or favourable job quality on MTW, it remains open whether a change of working conditions is associated 
with differences in MTW (de Wind et al., 2016, 2017; Fisher et al., 2016). Previous findings suggest that adverse or favourable working conditions may deplete or enhance MTW in the years approaching retirement age (Schreurs et al., 2011; Frins et al., 2016; Lichtenthaler and Fischbach, 2016; Nilsson, 2017; Polat et al., 2017). Moreover, they imply that - over the course of time - a reversal of exposure accumulation may allow workers to recover from a demanding work environment, thus enhancing MTW, particularly when a work environment improves quite early. Concurrently, a deteriorating work environment may deplete a worker's resources, thus impairing MTW. This effect may be more pronounced when a work environment deteriorates at an earlier point in time.

\section{Lack of research and study purpose}

To the authors' knowledge, there is no study investigating the entirety of job quality, as well as its accumulated effects on MTW, in a representative sample of the older workforce in Germany. Yet, when it comes to EWL, monitoring groups of workers to whom certain job quality constellations apply at a given point of time in working life and linking those trajectories to a specific motivation salient to them in this context, both may allow estimation of the accumulated work exposure effects for premature or delayed retirement (Wang and Shultz, 2010; Hofäcker and Naumann, 2015; Ebener, 2019). Such knowledge could also help enterprises and policy makers to adjust measures directed at raising employment participation (Federal Ministry for Economic Affairs and Energy, 2016; Taylor et al., 2016), while considering disadvantaged workers concomitantly (Hofäcker and Naumann, 2015; Bujacz et al., 2018; König et al., 2019; Hasselhorn, 2020a; Ní Léime et al., 2020) and thereby increasing efficiency and fairness of EWL strategies.

To summarise, the research aim of the present study is twofold. First, structural stability of job quality profiles will be addressed by exploring whether and how their prevalence changes within a representative sample of workers in the German babyboomer generation. In addition, individual profile stability will be explored by focusing on the qualitative direction that workers transfer between profiles over time. Second, workers with selected trajectories regarding timing and qualitative direction of job quality change will be examined with regard to differences in MTW at the end of the assessment period. In this context, it is hypothesised for both manual as well as non-manual workers that:

- Hypothesis 1 (H1): those with constant favourable job quality exhibit the highest and the adverse counterpart the lowest MTW levels.

- Hypothesis 2 (H2): an early change from adverse to favourable job quality is associated with higher MTW levels compared to constant adverse job quality.

- Hypothesis 3 (H3): an early change from favourable to adverse job quality is associated with lower MTW levels compared to constant favourable job quality.

- Hypothesis 4 (H4): a later change from adverse to favourable job quality is associated with lower MTW levels compared to an early change.

- Hypothesis 5 (H5): a later change from favourable to adverse job quality is associated with higher MTW levels compared to an early change. 


\section{Methods}

\section{Study design and sampling}

We used data from the German 'leben in der Arbeit' (lidA; German for 'living at work') study on work, age, health and employment participation (www.lida-studie. de). lidA is a prospective cohort study focusing on the transition from work to retirement in two German baby-boomer cohorts born in 1959 or 1965 (Hasselhorn et al., 2014). Participants were randomly drawn in a two-stage sampling procedure and surveyed via computer-assisted personal interviews at their homes in $2011(\mathrm{~N}=6,585), 2014(\mathrm{~N}=4,244)$ and $2018(\mathrm{~N}=3,586)$. A cut-off of $50+$ years is used in many studies to define older workers, others already take 45 + years or 55+ years only (see e.g. Farrow and Reynolds, 2012: 5). According to the German Federal Employment Agency, workers aged 45+ already have a lowered employability (Dauth and Toomet, 2016). Thus, regarding the German labour market, both cohorts of the lidA study are considered relevant in this context to represent the older part of the German workforce. In 2011, the response rate (RR5) was 27.3 per cent and the co-operation rate (COOP3) was 32.6 per cent (according to the American Association for Public Opinion Research, 2016), which is similar to that of other German studies of comparable design (e.g. Klaus et al., 2017). In all three instances, the samples are representative for the socially insured working population (no self-employed or sworn civil servants) of the respective age cohort as of 31st December 2009, where initial sampling was planned. However, the younger cohort was deliberately oversampled to compensate for future loss to follow-up (Table 1; Schröder et al., 2013; Steinwede et al., 2015, 2018). A detailed study design and cohort profile is found in Hasselhorn et al. (2014). As shown in Table 1, there were minor differences between the cohort's distribution of educational level and self-rated health across assessments.

Participants were included in the final sample if they were subject to social insurance contributions and employed for at least one hour per week in each assessment. To first investigate profile development over time, participants for whom valid profile data (see below) were available for all three assessments were selected $(\mathrm{N}=2,863 ; c f$. Table 1$)$. In each cohort of this final complete-case sample, the distribution of sex, educational level, weekly working hours and self-rated health did not differ significantly from that of the total 2018 sample. ${ }^{1}$ For the second part of the analyses, a sub-sample of these $\mathrm{N}=2,863$ was drawn which was comprised of workers with specific manual and non-manual job quality trajectories that correspond to the study hypotheses. Hence, for the second analyses part the sample size reduced to $\mathrm{N}=1,582$, which represents 55.2 per cent of the complete-case study sample.

\section{Measures}

Job quality trajectories

This article builds on earlier research based on lidA data from 2011 in which the above-described job quality profiles were empirically identified by means of LPA (Hasselhorn et al., 2020b). These profiles intend to capture qualitative different work environments of the older German workforce by means of distinct constellations of the following nine job quality characteristics: physical exposure, work time 
Table 1. Sociodemographic characteristics (valid \%) for the samples per assessment years and for the final study sample by cohort

\begin{tabular}{|c|c|c|c|c|c|c|c|c|c|c|c|c|c|c|c|c|}
\hline & \multicolumn{4}{|c|}{$2011(N=6,585)$} & \multicolumn{4}{|c|}{$2014(\mathrm{~N}=4,244)$} & \multicolumn{4}{|c|}{$2018(N=3,586)$} & \multicolumn{4}{|c|}{ Study sample $(N=2,863)$} \\
\hline & \multicolumn{2}{|c|}{ Cohort 1959} & \multicolumn{2}{|c|}{ Cohort 1965} & \multicolumn{2}{|c|}{ Cohort 1959} & \multicolumn{2}{|c|}{ Cohort 1965} & \multicolumn{2}{|c|}{$\begin{array}{c}\text { Cohort } \\
1959\end{array}$} & \multicolumn{2}{|c|}{ Cohort 1965} & \multicolumn{2}{|c|}{$\begin{array}{c}\text { Cohort } \\
1959\end{array}$} & \multicolumn{2}{|c|}{ Cohort 1965} \\
\hline & $\mathrm{N}$ & $\%$ & $\mathrm{~N}$ & $\%$ & $\mathrm{~N}$ & $\%$ & $\mathrm{~N}$ & $\%$ & $\mathrm{~N}$ & $\%$ & $\mathrm{~N}$ & $\%$ & $\mathrm{~N}$ & $\%$ & $\mathrm{~N}$ & $\%$ \\
\hline \multicolumn{17}{|l|}{ Sex: } \\
\hline Male & 1,333 & 45.8 & 1,730 & 47.0 & 841 & 43.8 & 1,074 & 46.3 & 709 & 43.7 & 901 & 46.1 & 574 & 44.5 & 721 & 46.0 \\
\hline Female & 1,575 & 54.2 & 1,947 & 53.0 & 1,081 & 56.2 & 1,248 & 53.7 & 915 & 56.3 & 1,055 & 53.9 & 717 & 55.5 & 848 & 54.0 \\
\hline \multicolumn{17}{|c|}{ Educational level: } \\
\hline Low & 843 & 29.3 & 866 & 23.7 & 482 & 25.3 & 470 & 20.3 & 384 & 23.9 & 393 & 20.2 & 297 & 23.1 & 280 & 17.9 \\
\hline Medium & 1,473 & 51.2 & 2,026 & 55.5 & 1,016 & 53.4 & 1,342 & 58.1 & 872 & 54.2 & 1,129 & 58.0 & 690 & 53.8 & 921 & 59.0 \\
\hline High & 562 & 19.5 & 757 & 20.7 & 406 & 21.3 & 498 & 21.6 & 354 & 22.0 & 424 & 21.8 & 296 & 23.1 & 361 & 23.1 \\
\hline \multicolumn{17}{|c|}{ Weekly working hours: } \\
\hline$\leqslant 19$ & 263 & 9.7 & 381 & 10.9 & 174 & 9.9 & 206 & 9.7 & 152 & 10.8 & 150 & 8.5 & 121 & 9.9 & 114 & 7.6 \\
\hline $20-34$ & 577 & 21.2 & 695 & 20.0 & 364 & 20.8 & 428 & 20.2 & 349 & 24.9 & 445 & 25.3 & 305 & 24.9 & 374 & 25.1 \\
\hline$\geqslant 35$ & 1,884 & 69.2 & 2,407 & 69.1 & 1,211 & 69.2 & 1,490 & 79.2 & 903 & 64.3 & 1,161 & 66.1 & 798 & 65.2 & 1,005 & 67.3 \\
\hline \multicolumn{17}{|c|}{ Self-rated health status: ${ }^{1}$} \\
\hline Poor & 1,384 & 49.7 & 1,493 & 42.0 & 961 & 52.6 & 980 & 44.3 & 785 & 53.0 & 884 & 47.7 & 677 & 53.1 & 733 & 46.9 \\
\hline Good & 1,401 & 50.3 & 2,060 & 58.0 & 865 & 47.4 & 1,234 & 55.7 & 696 & 47.0 & 970 & 52.3 & 598 & 46.9 & 830 & 53.1 \\
\hline
\end{tabular}

Notes: Frequencies not adding up to the respective total sample size are due to missing values. 1 . Dichotomised as poor $=$ very poor $/$ poor $/$ satisfactory, good $=$ good/very good. 
quality, work intensity, skills and discretion, social environment, leadership quality, continued education, earnings and prospects. Apart from both the continued education and the earnings index, the remaining seven indices are the composite of several single items and/or established scales following the index construction approach of Eurofound (2016). ${ }^{2}$ The final five-profile solution demonstrated relative structural stability in the initial LPA. Validity of the five profiles was given through diverging patterns of association over time with physical and mental health, work-privacy conflict and work ability, thus representing distinct subgroups of the older working population. For the present study, participants were assigned a profile in the 2014 and 2018 assessment per highest posterior probability estimated with the equation of the initial latent profile model from the 2011 assessment (computed with LatentGOLD 5.1 $1^{\circ}$. Mean posterior probabilities per profile in 2011/ 2014/2018 indicated reliable classification and were as follows: for PQ they were $0.86 / 0.85 / 0.82$, for RM $0.84 / 0.83 / 0.83$, for SnM $0.84 / 0.85 / 0.89$, for SR $0.85 / 0.85$ / 0.88 and for HF $0.94 / 0.96 / 0.98$. Next, the small HF profile was merged with the conceptually similar SR profile for appropriate group sizes in subsequent analyses and to facilitate interpretability (all done in IBM SPSS Statistics $25^{\circ}$ ). Missing values inspection on the profile indices yielded proportions below 1.0 per cent in most instances with missings on three indices ranging from 1.4 to 4.7 per cent in single assessments. Corresponding to the mean refusal rate in Europe for disclosing earnings (Eurofound, 2016), the proportions of missing values for earnings were albeit higher (19.9\% in 2011, 15.9\% in 2014 and $18.2 \%$ in 2018) and were replaced by means of stochastic regression imputation (Enders, 2010). Sensitivity analyses showed that loss to follow-up and unemployment occurred to a small degree, with slightly higher proportions in the manual profiles in both instances.

Job quality trajectories were coded depending on the respective profile assignment per assessment, resulting in a total of $4 \times 4 \times 4=64$ trajectories. Due to initial oversampling, the group size of the younger cohort was slightly larger. As this was the case for all trajectories, it was decided consequently to analyse both cohorts jointly. To address the study hypotheses specifically, 12 of these 64 trajectories were selected to allow for plausible group comparisons, while the remaining 52 trajectories were discarded. Constant assignment of predominantly manual workers to adverse job quality in 2011, 2014 and 2018 is depicted by the PQ-PQ-PQ trajectory group and by RM-RM-RM for constant favourable job quality. An early change (between 2011 and 2014) from favourable to adverse job quality is depicted by the RM-PQ-PQ trajectory group and a later change (between 2014 and 2018) from adverse to favourable by the PQ-PQ-RM trajectory group, respectively. This was done by analogy for predominantly non-manual workers (SnM, SR). All trajectories are displayed in Tables 3 and 4.

\section{Occupational change}

Occupational change was assessed in 2014 and 2018 and is included as ancillary variables to determine the nature of profile change before further investigating MTW differences between the selected trajectories (cf. Table 3). Participants were asked to indicate whether they (a) had changed their employer since the last interview (yes/no) and (b) whether their profession had remained the same since the last interview (yes/no). 
Motivation to work

The outcome measure developed initially for the 2018 assessment was the 'motivation to work' scale (MTW; Ebener and Stiller, 2019). It intends to capture key aspects of MTW via self-report on a five-point rating scale ranging from 1 $=$ 'does not apply at all' to $5=$ 'fully applies'. The respective items are (translated from German): 'I consider it highly probable that I am going to work until statutory retirement age', 'The earlier I can quit working the better' (reverse-coded), 'I would like to work beyond statutory retirement age', 'I cannot even imagine that I am ever going to stop working' and 'I feel I am going to miss my work when I think about retirement' $(\omega=0.75)$. Confirmatory factor analyses supported a one-factorial congeneric model, with metric invariance holding across sexes. Considering the different statutory retirement ages applying to each cohort (1959 cohort: 66.2 years; 1965 cohort: 67.0 years), attention was paid to construct a content-free scale, i.e. without items mentioning specific retirement ages or conditions like health/finances, to prevent response bias resulting from the difference in remaining working years. Consequently, the 1959 (mean $=2.33$, standard deviation $(\mathrm{SD})=0.98$ ) and the 1965 cohort $($ mean $=2.38, \mathrm{SD}=0.89)$ did not differ significantly in mean MTW levels, $t(3213)=-1.5, p=0.145$. Further, MTW scores have high correlatation with desired and planned retirement age (Pearson $r=0.58$ and $r=0.52$ ) and low correlatation with intrinsic work motivation (Pearson $r=0.20$ ) and self-rated health (Spearman rho $=0.17$ ), suggesting a construct-wise valid interpretation of MTW scores (Ebener and Stiller, 2019). A mean value was computed for each participant with higher values representing higher MTW levels.

To verify profile adversity and favourability in the final study sample $(\mathrm{N}=2,863)$, mean MTW differences in 2018 were tested with an analysis of variance (ANOVA) between job quality profiles prior to the final analyses. A main effect was found for profile assignment in $2018, F(3,2,859)=13.9, p<0.001, \eta^{2}=0.02$. Workers in RM or SR displayed higher MTW levels compared to those in PQ and SnM, respectively (both $p<0.001$ ). A comparison between RM and SR as well as between PQ and SnM did not indicate significant differences though (both $p=1.0$ ), suggesting that RM and SR represent favourable and PQ and SnM represent adverse job quality profiles regarding MTW (for mean values, see Table 4). To further rule out the possibility of bias attributable to the selection of specific trajectories as outlined above, mean MTW scores of the selected participants with manual (mean $=2.36, \mathrm{SD}=0.93 ; \mathrm{N}=$ 491) and non-manual trajectories (mean $=2.37, \mathrm{SD}=0.94 ; \mathrm{N}=1,091$ ) were tested against those excluded from later MTW analyses (mean $=2.33, \mathrm{SD}=0.90 ; \mathrm{N}=$ $1,281)$. However, there was no main effect regarding mean differences between those groups, $F(2,2,860)=0.6, p=0.551$, suggesting absence of selection bias.

\section{Statistical analyses}

Structural changes between profiles over time were explored comparing profile proportions between assessments descriptively and with one-dimensional $\chi^{2}$-tests. The association between profile assignment and assessment year was tested with a threeway log-linear analysis. Odds ratios (OR) were calculated to assess the degree of association for a certain profile assignment (reference: assignment to any other profile). Hypothesised mean differences on MTW scores were tested between the 
selected trajectory groups with planned non-orthogonal contrasts (one-tailed), applying a Bonferroni-Holm correction to an $\alpha$-level of 0.05 (Bortz and Schuster, 2010: 232). Effect sizes with Hedges $g \geqslant 0.20$ were classified as small, $g \geqslant 0.50$ as medium and $g \geqslant 0.80$ as large (Cohen, 1988).

\section{Results}

\section{Structural and individual profile stability}

First, profile development was explored across assessments. As depicted on the left side of Table 2 (and graphically in Figure 2), the two predominantly manual profiles, PQ and RM, decreased in size from 2011 until 2018, while the non-manual profiles, SnM and SR, increased, $\chi^{2}(3)=284.5, p<0.001$. This trend was apparent for PQ and SnM in the first observation period already, $\chi^{2}(3)=8.7, p=0.034$, but even more so for all four profiles in the second assessment period, $\chi^{2}(3)=$ $218.3, p<0.001$, indicating that over time older employees shifted to less physically demanding profiles, especially when former job quality was adverse.

Next, the log-linear analysis produced a final model that retained all two-way interactions, $\chi^{2}(27)=32.7, p=0.206$ (right column in Table 2). For the $2011 \times$ 2014 interaction $\left(\chi^{2}(9)=684.5, p<0.001\right)$, the highest OR in 2014 were obtained for profile continuity: e.g. for all 474 workers assigned to PQ in 2011, OR to remain there in 2014 were 7.4. The respective OR for RM were 6.2, for SnM 4.6 and for SR 7.5. The OR for PQ to switch to RM were 1.4 and 1.1 and vice versa, indicating a somewhat higher association between manual profiles.

Regarding the significant $2014 \times 2018$ interaction $\left(\chi^{2}(9)=479.1, p<0.001\right)$, the assignment pattern for the manual profiles reported above was even more pronounced. Among the non-manual profiles, profile continuity dropped for SnM from $\mathrm{OR}=4.6$ to 3.6 and for $\mathrm{SR}$ from $\mathrm{OR}=7.5$ to 5.8 . This, however, may be attributed to the increasing total size of the non-manual profiles to which manual workers had shifted in the meantime. A detailed report of the significant $2011 \times 2018$ interaction $\left(\chi^{2}(9)=231.7, p<0.001\right)$ is omitted as the OR largely resemble those of the $2014 \times 2018$ interaction. To summarise, these patterns indicate a certain degree of profile continuity, yet profile changes are apparent for large shares of the sample, especially within the manual and non-manual profiles, respectively (see Figure 2).

Regarding individual profile stability, 3.0 per cent of the sample stayed in PQ across all three assessments. The proportions were 7.2 per cent for those constantly in RM, 3.6 per cent for SnM and 21.3 per cent for SR, adding up to a constant seven-year job quality for 35.1 per cent of all participants studied. Hence, nearly two-thirds of the sample experienced varying degrees of job quality change over time (cf. Figure 2).

\section{Occupational and profile change}

Before the second analyses, we inspected whether a profile change was preceded by a change of employer or profession in the trajectories selected for MTW analyses $(\mathrm{N}=1,582)$, as such an association might obscure the hypothesised job quality effects on MTW. As documented in Table 3, occupational change was rarely 
Table 2. Profile size and percentage assignment with odds ratios for job quality profiles by assessment year

\begin{tabular}{|c|c|c|c|c|c|c|c|c|c|}
\hline & \multirow[b]{2}{*}{$\mathrm{N}(\%$ of 2,863$)$} & \multicolumn{2}{|c|}{$\mathrm{PQ}$} & \multicolumn{2}{|c|}{$\mathrm{RM}$} & \multicolumn{2}{|c|}{ SnM } & \multicolumn{2}{|c|}{ SR } \\
\hline & & $\%$ & OR & $\%$ & OR & $\%$ & OR & $\%$ & OR \\
\hline 2011 assignment: & & \multicolumn{8}{|c|}{2014 assignment } \\
\hline $\mathrm{PQ}$ & $474(16.6)$ & 42.8 & 7.4 & 33.1 & 1.4 & 15.0 & 0.8 & 9.1 & 0.1 \\
\hline RM & 779 (27.2) & 15.3 & 1.1 & 55.2 & 6.2 & 7.4 & 0.2 & 21.1 & 0.3 \\
\hline SnM & $477(16.7)$ & 13.0 & 0.8 & 11.1 & 0.3 & 41.4 & 4.6 & 34.4 & 0.8 \\
\hline SR & $1,133(39.6)$ & 3.5 & 0.1 & 12.0 & 0.2 & 16.7 & 0.9 & 67.8 & 7.5 \\
\hline$\%$ of 2,863 in 2014 & & 14.8 & & 27.1 & & 18.0 & & 40.1 & \\
\hline 2014 assignment: & & \multicolumn{8}{|c|}{2018 assignment } \\
\hline$P Q$ & $424(14.8)$ & 34.9 & 7.8 & 21.9 & 1.4 & 24.8 & 1.1 & 14.8 & 0.2 \\
\hline $\mathrm{RM}$ & $776(27.1)$ & 14.2 & 1.6 & 40.5 & 6.6 & 13.3 & 0.3 & 32.1 & 0.4 \\
\hline SnM & $516(18.0)$ & 5.0 & 0.4 & 6.4 & 0.3 & 45.9 & 3.8 & 42.6 & 0.8 \\
\hline SR & $1,047(40.1)$ & 1.8 & 0.1 & 5.9 & 0.2 & 19.3 & 0.7 & 73.0 & 5.8 \\
\hline$\%$ of 2,863 in 2018 & & 10.7 & & 17.7 & & 23.3 & & 48.3 & \\
\hline
\end{tabular}

Notes: $\mathrm{N}=2,863$. OR: odds ratio for respective profile assignment (reference: assignment to any other profile in the respective assessment). PQ: Poor Quality. RM: Relaxed Manual. SnM: Strained non-Manual. SR: Smooth Running.

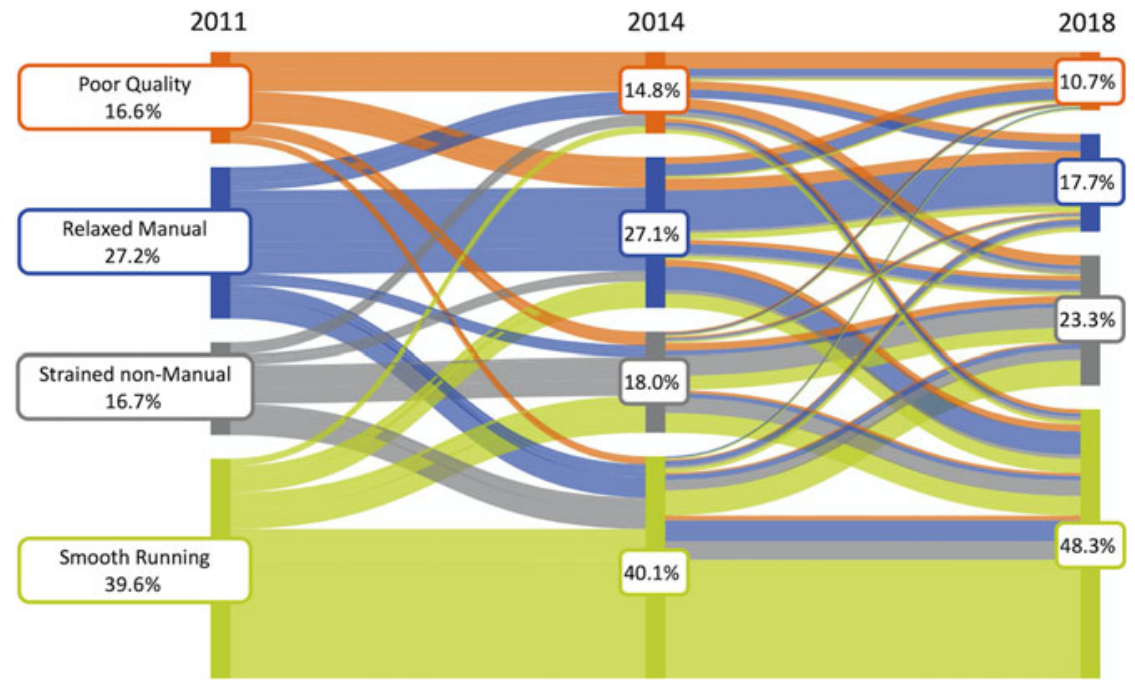

Figure 2. Job quality profiles for older employees in Germany across seven years Notes: $\mathrm{N}=2,863$. Trajectories with $\mathrm{N}<4$ cannot be displayed for reasons of data protection.

observed. On average, change of employer (8.2\%) and profession (6.9\%) were less frequent between 2011 and 2014 than between 2014 and 2018 (11.1 and 9.5\%, respectively). Beyond that, occupational change occurred somewhat more frequent 
Table 3. Proportion of workers (\% of $\mathrm{N}$ ) per trajectory group with change of employer or profession in each follow-up period

\begin{tabular}{|c|c|c|c|c|c|c|c|c|}
\hline \multirow[b]{3}{*}{ Trajectory } & \multicolumn{4}{|c|}{ Change between 2011 and 2014} & \multicolumn{4}{|c|}{ Change between 2014 and 2018} \\
\hline & \multicolumn{2}{|c|}{ Employer } & \multicolumn{2}{|c|}{ Profession } & \multicolumn{2}{|c|}{ Employer } & \multicolumn{2}{|c|}{ Profession } \\
\hline & $\mathrm{N}$ & $\%$ of $\mathrm{N}$ & $\mathrm{N}$ & $\%$ of $\mathrm{N}$ & $\mathrm{N}$ & $\%$ of $\mathrm{N}$ & $\mathrm{N}$ & $\%$ of $\mathrm{N}$ \\
\hline \multicolumn{9}{|l|}{ Manual: } \\
\hline$P Q-P Q-P Q$ & 86 & 7.0 & 85 & 3.5 & 86 & 8.1 & 85 & 2.4 \\
\hline RM-RM-PQ & 58 & 10.3 & 57 & 5.3 & 58 & 10.3 & 57 & 7.0 \\
\hline RM-PQ-PQ & 38 & 13.2 & 38 & 7.9 & 38 & 13.2 & 38 & 10.5 \\
\hline RM-RM-RM & 205 & 14.6 & 206 & 8.3 & 205 & 16.6 & 205 & 12.2 \\
\hline PQ-PQ-RM & 43 & 11.6 & 43 & 7.0 & 42 & 26.2 & 43 & 23.3 \\
\hline PQ-RM-RM & 61 & 19.7 & 61 & 11.5 & 60 & 26.7 & 60 & 23.3 \\
\hline \multicolumn{9}{|l|}{ Non-manual: } \\
\hline SnM-SnM-SnM & 104 & 4.8 & 103 & 7.8 & 103 & 4.9 & 104 & 7.7 \\
\hline SR-SR-SnM & 125 & 5.6 & 130 & 6.2 & 125 & 5.6 & 130 & 8.5 \\
\hline SR-SnM-SnM & 71 & 0.0 & 71 & 1.4 & 71 & 5.6 & 72 & 4.2 \\
\hline SR-SR-SR & 587 & 6.3 & 607 & 6.6 & 582 & 8.4 & 596 & 8.7 \\
\hline SnM-SnM-SR & 80 & 7.5 & 79 & 3.8 & 78 & 20.5 & 79 & 6.3 \\
\hline SnM-SR-SR & 92 & 8.7 & 96 & 13.5 & 88 & 12.5 & 94 & 11.7 \\
\hline
\end{tabular}

Notes: $\mathrm{N}=1,582$. Differences in total sample size are due to missing values per occupational change variable and assessment year. PQ: Poor Quality. RM: Relaxed Manual. SnM: Strained non-Manual. SR: Smooth Running. PQ-PQ-PQ, etc.: trajectory group (as per 2011, 2014 and 2018 profile assignment).

among the manual job quality trajectories, especially among those with constant or changing to favourable job quality. For single trajectories, where timing of profile change and a higher proportion of occupational change co-occurred during the second follow-up period (PQ-PQ-RM and SnM-SnM-SR), a reversed pattern was not observable in the first follow-up period (PQ-RM-RM and SnM-SRSR). To summarise, no clear systematics can be observed that reveal occupational change as a determinant of job quality profile change among the selected manuals and non-manuals, respectively.

\section{Trajectory effects on MTW}

In the final MTW analyses testing the study hypotheses, a significant Levene's test indicated heteroscedasticity, $F(11,1,570)=3.7, p<0.001$, and as the groups also differed in size ( $c f$. Table 4), a robust Welch ANOVA was conducted accordingly. There was a significant main effect for trajectory groups on MTW, Welch's $F(11$, 334.23) $=5.6, p<0.001, \eta^{2}=0.03$.

As hypothesised in $\mathrm{H1}$, manual employees with constant favourable job quality (RM-RM-RM) exhibited higher MTW levels than the adverse counterpart 
Table 4. Descriptive statistics for motivation to work scores by 2018 profile assignment and selected trajectory group

\begin{tabular}{|c|c|c|c|c|c|c|}
\hline \multirow[b]{2}{*}{ Profile } & \multirow[b]{2}{*}{ N } & \multirow[b]{2}{*}{$\%$ of $\mathrm{N}$} & \multicolumn{2}{|c|}{2018 assignment } & \multicolumn{2}{|c|}{$\begin{array}{l}\text { Selected } \\
\text { trajectory }\end{array}$} \\
\hline & & & Mean & SD & Mean & SD \\
\hline$P Q$ & 305 & 10.7 & 2.15 & 0.92 & - & - \\
\hline $\mathrm{RM}$ & 508 & 17.7 & 2.46 & 0.93 & - & - \\
\hline SnM & 666 & 23.3 & 2.20 & 0.86 & - & - \\
\hline SR & 1,384 & 48.3 & 2.43 & 0.94 & - & - \\
\hline \multicolumn{7}{|l|}{ Manual: } \\
\hline PQ-PQ-PQ & 86 & 3.0 & - & - & 2.04 & 0.80 \\
\hline RM-RM-PQ & 58 & 2.0 & - & - & 2.23 & 0.95 \\
\hline $\mathrm{RM}-\mathrm{PQ}-\mathrm{PQ}$ & 38 & 1.3 & - & - & 2.37 & 0.93 \\
\hline RM-RM-RM & 206 & 7.2 & - & - & 2.55 & 0.97 \\
\hline PQ-PQ-RM & 42 & 1.5 & - & - & 2.06 & 0.72 \\
\hline PQ-RM-RM & 61 & 2.1 & - & - & 2.51 & 0.90 \\
\hline \multicolumn{7}{|l|}{ Non-manual: } \\
\hline SnM-SnM-SnM & 104 & 3.6 & - & - & 2.22 & 0.87 \\
\hline SR-SR-SnM & 130 & 4.5 & - & - & 2.12 & 0.74 \\
\hline SR-SnM-SnM & 72 & 2.5 & - & - & 2.16 & 0.83 \\
\hline SR-SR-SR & 609 & 21.3 & - & - & 2.46 & 0.97 \\
\hline SnM-SnM-SR & 80 & 2.8 & - & - & 2.22 & 0.83 \\
\hline SnM-SR-SR & 96 & 3.4 & - & - & 2.55 & 1.10 \\
\hline
\end{tabular}

Notes: $N=2,863$ (workers with selected trajectories $(N=1,582)$ correspond to $55.2 \%$ of $N=2,863)$. SD: standard deviation. PQ: Poor Quality. RM: Relaxed Manual. SnM: Strained non-Manual. SR: Smooth Running. PQ-PQ-PQ, etc.: trajectory group (as per 2011, 2014 and 2018 profile assignment).

(PQ-PQ-PQ), $t(192)=4.7, p<0.001, g=0.55,95 \%$ confidence interval $(\mathrm{CI})=0.30$; 0.81 (see Table 4). An early change from adverse to favourable (PQ-RM-RM) enhanced MTW compared to those with constant adverse job quality (PQ-PQ$\mathrm{PQ}$ ), thus confirming $\mathrm{H} 2, t(119)=3.2, p=0.001, g=0.56,95 \% \mathrm{CI}=0.22 ; 0.89$. Contrary to the prediction in $\mathrm{H} 3$, the reversed effect (RM-PQ-PQ compared to $\mathrm{RM}-\mathrm{RM}-\mathrm{RM}$ ) was not significant, $t(53)=1.1, p=0.139$. A later change from adverse to favourable $(\mathrm{PQ}-\mathrm{PQ}-\mathrm{RM})$ resulted in lower MTW levels than those changing earlier (PQ-RM-RM), confirming H4, $t(99)=2.8, p=0.004, g=0.54,95 \% \mathrm{CI}=0.14 ; 0.94$. In contrast to the prediction in $\mathrm{H} 5$, there was no significant MTW difference between those with a later change from favourable to adverse (RM-RM-PQ) compared to those changing earlier (RM-PQ-PQ), $t(81)=0.8, p=0.227$ ( $c f$. Figure 3 ).

A comparable pattern emerged for the non-manual trajectory groups (cf. Table 4). As predicted in H1, constant favourable job quality (SR-SR-SR) resulted in higher MTW levels than in the adverse counterpart (SnM-SnM-SnM), 


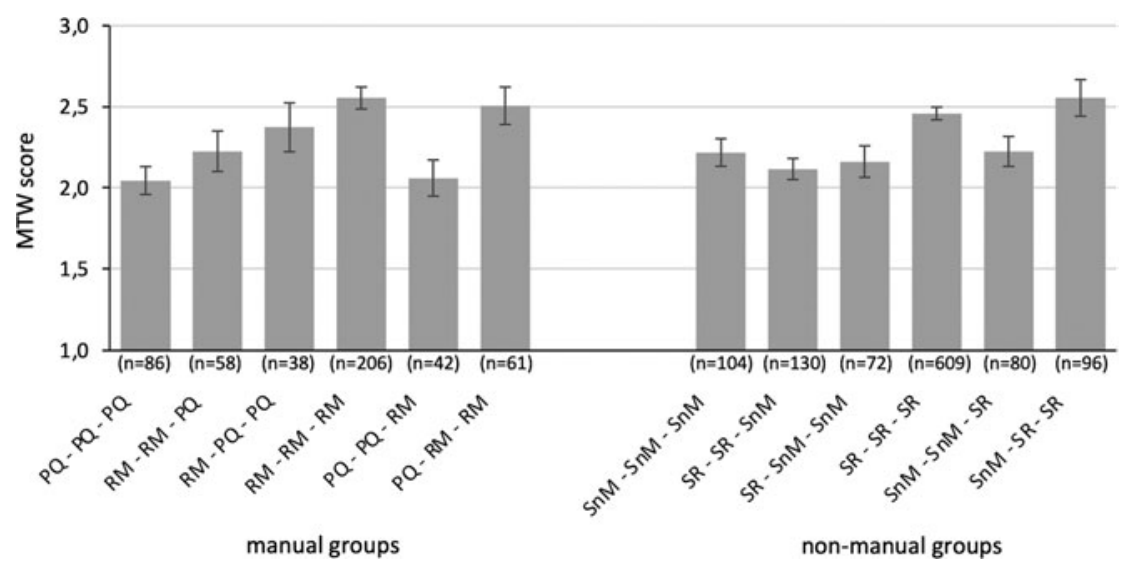

Figure 3. Mean motivation to work (MTW) scores (with standard errors) in 2018 for trajectory groups. Notes: PQ: Poor Quality. RM: Relaxed Manual. SnM: Strained non-Manual. SR: Smooth Running. PQ-PQ-PQ, etc.: trajectory group (as per 2011, 2014 and 2018 profile assignment).

$t(150)=2.6, p=0.006, g=0.25,95 \% \mathrm{CI}=0.04 ; 0.46$. An early change to the favourable profile (SnM-SR-SR) enhanced MTW compared to constant adverse job quality $($ SnM-SnM-SnM), confirming H2, $t(180)=2.4, p=0.009, g=0.33,95 \% \mathrm{CI}=0.06$; 0.61 . The reversed pathway (SR-SnM-SnM compared to SR-SR-SR) yielded significantly lower MTW levels, $t(96)=2.8, p=0.003, g=0.31,95 \% \mathrm{CI}=0.07$; 0.56. Thus, $\mathrm{H} 3$ is confirmed. In line with $\mathrm{H} 4$, a later change from adverse to favourable (SnM-SnM-SR) resulted in lower MTW levels compared to those changing earlier in a similar direction (SnM-SR-SR), $t(172)=2.3, p=0.013, g=0.33,95 \% \mathrm{CI}=$ $0.04 ; 0.63$. In contrast to the prediction in $\mathrm{H} 5$, a later change from favourable to adverse (SR-SR-SnM) did not reveal significantly different MTW levels from early changers in the same direction (SR-SnM-SnM), $t(134)=0.4, p=0.349$ (cf. Figure 3).

\section{Discussion}

This study revealed size and direction of job quality change among employed babyboomers in Germany in the years prior to retirement. First, a general move towards physically less-demanding job quality profiles was observed over time. Profile continuity was evident between assessments in all instances, yet the majority experienced some degree of job quality change across the seven-year observation period. Second, and as expected, those with constant favourable job quality exhibited the highest MTW levels and their respective adverse counterparts exhibited the lowest. Early changes rather than later changes between job quality profiles were associated with the expected MTW levels.

\section{Frequency and direction of profile change}

Changes in the work environment seem to occur frequently among German babyboomer cohorts. The move from manual to predominantly non-manual profiles found in our study is in line with previous findings by Bujacz et al. (2018) 
who - over six years - found that workers in profiles characterised by high workload and time pressure moved to profiles with lower levels of demands. However, the study by Bujacz et al. (2018) was restricted to psychosocial working conditions among high-skilled workers, whereas the conceptual approach applied in the present study allows for a more nuanced picture. The general move to both nonmanual profiles is associated with slightly higher work intensity, but also with less physical exposure, better working time quality, better psychosocial resources, continued education and higher earnings as compared to both manual profiles. These qualitative changes might reflect ageing-related adjustments to decreasing physical resources (König et al., 2019) and family obligations that gain individual importance in the last working years (Baltes et al., 2012; Amick et al., 2016). It remains open as to what determines a switch from one job quality profile to the other among manuals and non-manuals, respectively. As was shown for the 12 selected trajectories, change of employer or profession rarely occurred and were not associated systematically with a change in job quality profile. They may - at the most - explain MTW differences between the trajectories only to a small extent. Other forms of occupational change, such as changes in work tasks (Wong and Tetrick, 2017; Garthe and Hasselhorn, in press), may alter a worker's job quality characteristics. They may occur voluntarily, when initiated by the employee, or involuntarily, e.g. when imposed by the organisation (Garthe and Hasselhorn, in press). They may be further associated with cascading effects, when leadership quality changes due to a new supervisor, which in turn might lead to secondary changes in other job quality characteristics (Wong and Tetrick, 2017). For several reasons, the desire for occupational change often remains unfulfilled for large proportions of workers in the years preceding retirement (Garthe and Hasselhorn, in press). This could provide another possible explanation why quality of work continues to be low for some groups of employees. Such potential mechanisms cannot be identified within the current study. Yet, they require thorough investigation in future research to enhance the understanding of dynamics in job quality in later working life.

\section{MTW differences between trajectory groups}

Constant job quality was associated with MTW in the expected direction, indicating the presence of accumulating effects of adverse and favourable work exposure on MTW (as assumed in H1). Moreover, changes in job quality seem to be of relevance for MTW in later working life, as the qualitative direction and timing of change were significantly associated with different MTW levels in most instances. Higher MTW levels among those whose trajectory changed between 2011 and 2014 to favourable exposure (as assumed in H2) may represent a form of motivational enhancement resulting from sufficient compensation for prior adverse job quality. On the other hand, and in line with H4, a change between 2014 and 2018 to favourable exposure resulted in lower MTW levels compared to those changing earlier, suggesting that compensatory effects for prior adverse job quality require at least four years of favourable work exposure to enhance MTW substantially. In partial agreement with H3, a change between 2011 and 2014 from favourable to adverse profiles resulted in lower MTW levels, yet this was found for non-manual workers 
only. This might possibly be explained by the relatively low earnings in both manual groups ( $c f$. Figure 1). In contrast to non-manual workers, manuals may well depend on working longer for financial objectives (Hofäcker and Naumann, 2015), regardless of their physical condition and the adversities they may be exposed to at work (Hasselhorn et al., 2020a). Moreover, manual workers might potentially react with a longer time lag to adverse job quality changes regarding their MTW. In either case, further monitoring is required, as the observation period might have been too short to detect the hypothesised effects for the manual trajectory groups, but also to identify preconditions that differentially predict MTW levels of manual and non-manual trajectory groups in addition to prior job quality changes. Finally, and contrary to H5, a change between 2014 and 2018 from favourable to adverse profiles did not result in higher MTW levels than a change between 2011 and 2014. As discussed for early changes of manuals (in H3), older age groups of the working population may not react as immediately to adverse job quality changes as expected. In addition, these changes might also conflict with other motives and attitudes of the ageing worker, thus preventing alternation of MTW as expected (Kooij et al., 2011; Baltes et al., 2012; Radl, 2012; Wong and Tetrick, 2017; Franke and Simonson, 2018). This opens up a new line of research as it is unclear at the moment whether the observation period was too short and/or whether the manual trajectory groups display a different reaction pattern to adverse job quality changes in general.

The obtained effect sizes for MTW differences were small for non-manual and medium for the manual trajectory groups, suggesting that job quality may play a greater role for work motivational objectives among the latter. Considering our findings, it may be surprising to find EWL policies to be unconnected to work quality. The findings indicate that EWL measures directed at enhancing job quality early may be particularly relevant for workers in manual jobs, where accumulated adverse work exposures (as represented by the PQ profile) have the greatest potential for putting health and well-being at risk (Bujacz et al., 2018; König et al., 2019; Hasselhorn, 2020a; Hasselhorn et al., 2020b; Ní Léime et al., 2020). Current 'one-size-fits-all' EWL policies (Phillipson, 2019; Ní Léime et al., 2020) not accounting for such working-life exposures are at risk of systematically exacerbating social inequalities, with serious long-term consequences for those confronted with the pressure to continue working (König et al., 2019), regardless of their resources to accommodate these labour market demands (Hasselhorn, 2020a; Ní Léime et al., 2020).

This is the first study to investigate stability of the entirety of job quality in a representative sample of workers in a single country and, furthermore, to establish a direct link to their MTW. In doing so, the conceptual approach of Eurofound ( $c f$. Eurofound, 2016) has been expanded to longitudinal data which made detecting changes beyond psychosocial working conditions in a specific sample possible (cf. Bujacz et al., 2018). The pattern of MTW differences - as found for manual and non-manual trajectory groups - underscores the accumulated impact of job quality as a precursor of MTW. In the broader context of the work-retirement transition, the investigated job quality trajectories may have the potential to affect retirement indirectly, as differences in MTW may be associated with employment in the last working years (Hasselhorn and Ebener, 2018). 


\section{Strengths and limitations}

A major strength of the present study is the simultaneous investigation of changes in the entirety of working conditions (as in Eurofound, 2016), which allows for a differentiated understanding of the working situation employees undergo in the last working years (Baltes et al., 2012; Amick et al., 2016). For this purpose, a person-centred approach was applied by means of finite mixture modelling, with the addition of incorporating a temporal dimension. The observed MTW differences between trajectory groups suggest a minimum timeframe of four years for successful implementation and the extent to which measures directed at improving job quality may be effective. Finally, the findings were obtained for two babyboomer cohorts, representative for a large part of the German workforce who are about to transition to retirement in the near future (Schröder et al., 2013; Steinwede et al., 2015, 2018).

A limitation of the study is the measurement of MTW in the last assessment only, even though the authors are aware that it is preferred to account for previous MTW levels. It is possible that some workers with high MTW change their employer or occupation to maintain or even improve job quality, which implies reverse causation effects that cannot be investigated with the present study design. A further limitation is that not all possible trajectories ( $c f$. Figure 2) could be investigated in detail, as it was necessary to select a subset of trajectories that enabled subsequent plausible hypotheses testing and interpretability. For this purpose, a larger proportion of participants and their respective job quality trajectories had to be discarded. Furthermore, some of the omitted trajectories were too small in group size to allow for further statistical consideration. Even for the selected trajectory groups, small group sizes (e.g. $\mathrm{Nn}=38$ in the RM-PQ-PQ group) still may have prevented the detection of reliable differences, as their dispersion was accordingly high.

\section{Concluding remarks}

This study highlights the dynamic job quality situation of the baby-boomer generation in Germany and corroborates its importance for the changeability of MTW in later working life. From a scientific perspective, retirement research may profit from the longitudinal application of a person-centred approach to capture the older workforce in its complexity, as this proved useful in showing that experiencing different work environments in the later life course may have the potential to affect motivation to work longer. Moreover, when designing and implementing EWL strategies, the findings underline the need for policymakers to consider explicitly workers with long periods of poor job quality across later working life. Early interventions are needed, aiming to reconsider and sustainably improve quality of work to enable those with demanding work to stay longer in the labour market without further damage and disadvantage. This way, promoting longer working lives for workers with the resources available to postpone retirement would increase the overall efficiency and fairness of EWL measures.

Author contributions. MS and HMH designed the study, MS performed all analyses, MS wrote the first draft of the manuscript and NG and HMH contributed to its development. MS, NG and HMH critically reviewed and revised the manuscript and approved the final version. 
Financial support. The 2011 and 2014 waves of lidA were funded by the Federal Ministry of Education and Research (grant numbers 01ER0806, 01ER0825, 01ER0826, 01|ER0827). The 2018 wave of lidA was funded by the German Statutory Accident Insurance (Deutsche Gesetzliche Unfallversicherung; grant number FP-0403 lidA III). The funders were neither involved in designing, data collecting nor writing and submitting the present study.

Conflict of interest. The authors declare no conflicts of interest.

Ethical standards. Each participant was fully informed about the aim and procedure of this study in written form prior to giving verbal consent to participate. The verbal consent was then documented by the interviewer. Willingness for continued participation (to Waves 2 and 3) required written consent with an additional verbal consent (documented) at the beginning of the respective interview. The procedure was approved by the state privacy advocate of the Federal Ministry of Labour and Social Affairs (data protection contracts dating from July 2010 (8104.1-14) and 27 September 2017 (8102.9-23)). Ethical approval for study design and performance, including verbal and written consent, was obtained from the Ethics Committee of the University of Wuppertal (dated from 5 December 2008 (Sch/Ei Hasselhorn) and 20 November 2017 (MS/BB 171025 Hasselhorn)).

\section{Notes}

1 Cohort 1959: sex, $\chi^{2}(1)=0.3, p=0.581$; educational level, $\chi^{2}(2)=1.0, p=0.603$; weekly working hours, $\chi^{2}(2)=1.1, p=0.577$; self-rated health, $\chi^{2}(1)=0.0, p=0.944$. Cohort 1965: sex, $\chi^{2}(1)=0.0, p=0.907$; educational level, $\chi^{2}(2)=5.5, p=0.065$; weekly working hours, $\chi^{2}(2)=1.7, p=0.432$; self-rated health, $\chi^{2}(1)=$ $0.4, p=0.525$.

2 The respective indices were calculated as follows (weighting indicated in square brackets). The ordinal "physical exposure" index is the summed-up indication $(0=$ no, $1=$ yes $)$ of working time spend sitting [1], bending, kneeling/lying/working above head [1], lifting heavy loads [1] or with repetitive movements [1]. Raw sum scores were transformed to range 0-100. The ordinal "working time quality" index comprised the summed-up indication $(0=$ no, $1=$ yes $)$ of shift work [1], night shifts [1] and having another job [1]. Raw scores were transformed to range 0-100. The metric "work intensity" index consists of the four-item Copenhagen Psychosocial Questionnaire (COPSOQ) scale 'quantitative demands' [2] and the indication (0 $=$ no, $1=$ yes) of frequent interruptions at work [1]. After weighting, both components were summed up and transformed to range $0-100$. The metric "skills and discretion" index was the mean of the two three-item COPSOQ scales 'influence at work' [1] and 'possibilities for development' [1], already ranging from 0 to 100. The metric "social environment" index comprised the two-item COPSOQ scale 'support from colleagues' [1] with range 0-100 and the dichotomous effort-reward imbalance item 'receiving acknowledgement from colleagues' [1], where absence was coded with 0 and presence with 100 . The arithmetic mean was computed with range $0-100$. The metric "quality of leadership" index comprised the three-item COPSOQ scale 'quality of leadership' [3] with range 0-100 and the effort-reward imbalance item 'distress due to lack of recognition from superior' [1], where presence of recognition was coded with 25 . Lack of recognition was coded according to the distress induced, namely 'not at all' $=25$, 'moderate' $=16.67$, 'strong' $=8.33$ and 'very strong' $=0$. The COPSOQ scale was multiplied by 0.75 and both components were summed up, resulting in an index with range $0-100$. Participation in "continued education" in the last 12 months was a dichotomous item $(0=$ no, $1=$ yes). The metric "earnings" index was calculated as the monthly equivalised household net income. The ordinal "prospects index" was the summed-up indication $(0=$ no, $1=$ yes $)$ of fixed-term work contract [1], recent job cuts/dismissals in enterprise [1], risk of losing one's job [1], promotion prospects [1] and chances for occupational advancement [1]. Raw sum scores were transformed to range $0-100$. In the final LPA, the mixed scaling across indiceswas specified accordingly.

\section{References}

American Association for Public Opinion Research (2016) Standard Definitions: Final Dispositions of Case Codes and Outcome Rates for Surveys. Washington, DC: American Association for Public Opinion Research. 
Amick BC, McLeod CB and Bültmann U (2016) Labor markets and health: an integrated life course perspective. Scandinavian Journal of Work, Environment and Health 42, 346-453.

Baltes BB, Rudolph CW and Bal AC (2012) A review of aging theories and modern work perspectives. In Hedge JW and Borman WC (eds), The Oxford Handbook of Work and Aging. New York, NY: Oxford University Press, pp. 117-136.

Börsch-Supan A, Ludwig A, Heiss F and Winter J (2003) Pension reform, capital markets and the rate of return. German Economic Review 4, 151-181.

Bortz J and Schuster C (2010) Statistik für Human- und Sozialwissenschaftler. Berlin: Springer.

Bujacz A, Bernhard-Oettel C, Rigotti T, Magnusson Hanson L and Lindfors P (2018) Psychosocial working conditions among high-skilled workers: a latent transition analysis. Journal of Occupational Health Psychology 23, 223-236.

Cohen J (1988) Statistical Power Analysis for the Behavioral Sciences. Hillsdale, NJ: Lawrence Erlbaum Associates.

Dannefer D (2003) Cumulative advantage/disadvantage and the life course: cross-fertilizing age and social science theory. Journals of Gerontology: Psychological Sciences and Social Sciences 58B, 327-337.

Dauth C and Toomet $\mathbf{O}$ (2016) On government-subsidized training programs for older workers. Labour 4, 371-392.

de Wind A, van der Pas S, Blatter BM and van der Beek AJ (2016) A life course perspective on working beyond retirement - results from a longitudinal study in the Netherlands. BMC Public Health 16, 499.

de Wind A, Leijten FR, Hoekstra T, Geuskens GA, Burdorf A and van der Beek AJ (2017) 'Mental retirement?' Trajectories of work engagement preceding retirement among older workers. Scandinavian Journal of Work, Environment and Health 43, 34-41.

Dragano N and Schneider L (2011) Psychosoziale Arbeitsbelastungen als Prädiktoren der krankheitsbedingten Frühberentung: Ein Beitrag zur Beurteilung des Rehabilitationsbedarfs [Work-related psychosocial factors and the risk of early disability pensioning: a contribution to assessing the need for rehabilitation]. Die Rehabilitation 50, 28-36.

Ebener M (2019) Die Erfassung der Motivation, erwerbstätig zu sein, in arbeitswissenschaftlichen Studien. Wuppertal, Germany: Bergische Universität Wuppertal.

Ebener M and Stiller M (2019) Development of a 5-item scale measuring 'motivation to work' in the German working population. Paper presented at the 19th Congress of the European Association of Work and Organizational Psychology (EAWOP): 'Working for the Greater Good: Inspiring People, Designing Jobs and Leading Organizations for a More Inclusive Society', Turin, Italy, May/June.

Enders CK (2010) Applied Missing Data Analysis. New York, NY: Guilford Press.

European Foundation for the Improvement of Living and Working Conditions (Eurofound) (2016) Sixth European Working Conditions Survey - Overview Report. Luxembourg: Publications Office of the European Union.

Farrow A and Reynolds F (2012) Health and safety of the older worker. Occupational Medicine 62, 4-11.

Federal Ministry for Economic Affairs and Energy (2016) Annual Economic Report 2016. Ensuring Sustainability - Using the Opportunities of the Digital Transformation. Berlin: Federal Ministry for Economic Affairs and Energy (BMWi).

Federal Office of Statistics (2020) Labour Force Participation. Employed and Employment Rate by Sex and Age 2009 and 2019. Available at https://www.destatis.de/DE/Themen/Arbeit/Arbeitsmarkt/Erwerbstaetigkeit/ Tabellen/erwerbstaetige-erwerbstaetigenquote.html.

Fisher GG, Chaffee DS and Sonnega A (2016) Retirement timing: a review and recommendations for future research. Work, Aging and Retirement 2, 230-261.

Franke J and Simonson J (2018) Social justice beliefs regarding old-age provisions in Germany: a latent profile analysis. Social Justice Research 31, 182-205.

Frins W, van Ruysseveldt J, van Dam K and van den Bossche SN (2016) Older employees' desired retirement age: a JD-R perspective. Journal of Managerial Psychology 31, 34-49.

Garthe $\mathbf{N}$ and Hasselhorn HM (in press) Changes of profession, employer and work tasks in later working life: an empirical overview of staying and leaving. Ageing \& Society. Available online doi:10.1017/ S0144686X21000088.

Hasselhorn HM (2020a) Social inequality in the transition from work to retirement. In Theorell T (ed.), Handbook of Socioeconomic Determinants of Occupational Health (Handbook Series in Occupational Health Sciences). Cham, Switzerland: Springer, pp. 106-130. 
Hasselhorn HM (2020b) Wie lange wollen und können Erwerbstätige in Deutschland arbeiten? [How long do German employees desire and are able to work?]. Deutsche Rentenversicherung 75, 485-506.

Hasselhorn HM and Ebener M (2018) The differentiated role of health for employment participation among older workers - a discussion based on the 'lidA conceptual framework on work, age and employment'. In Hohnerlein EM, Hennion S and Kaufmann O (eds), Erwerbsverlauf und sozialer Schutz in Europa. Berlin: Springer, pp. 199-214.

Hasselhorn HM, Peter R, Rauch A, Schröder H, Swart E, Bender S, du Prel J-B, Ebener M, March S, Trappmann M, Steinwede J and Müller BH (2014) Cohort profile: the lidA cohort study - a German cohort study on work, age, health and work participation. International Journal of Epidemiology 43, 1736-1749.

Hasselhorn HM, Ebener M and Müller BH (2015) Determinanten der Erwerbsteilhabe im höheren Erwerbsalter-das 'lidA-Denkmodell zu Arbeit, Alter und Erwerbsteilhabe'. Zeitschrift für Sozialreform 61, 403-432.

Hasselhorn HM, Ebener M and Vratzias A (2020a) Household income and retirement perspective among older workers in Germany - findings from the lidA Cohort Study. Journal of Occupational Health 62, e12130.

Hasselhorn HM, Stiller M, du Prel J-B and Ebener M (2020b) Work profiles of older employees in Germany - results from the lidA-cohort study. BMC Public Health 20.

Hofäcker D (2015) In line or at odds with active ageing policies? Exploring patterns of retirement preferences in Europe. Ageing \& Society 35, 1529-1556.

Hofäcker D and Naumann E (2015) The emerging trend of work beyond retirement age in Germany. Zeitschrift für Gerontologie und Geriatrie 48, 473-479.

Kanfer R, Beier ME and Ackerman PL (2013) Goals and motivation related to work in later adulthood: an organizing framework. European Journal of Work and Organizational Psychology 22, 253-264.

Klaus D, Engstler H, Mahne K, Wolff JK, Simonson J, Wurm S and Tesch-Römer C (2017) Cohort profile: the German Ageing Survey (DEAS). International Journal of Epidemiology 46, 1105-1105g.

Knardahl S, Johannessen HA, Sterud T, Härmä M, Rugulies R, Seitsamo J and Borg V (2017) The contribution from psychological, social, and organizational work factors to risk of disability retirement: a systematic review with meta-analyses. BMC Public Health 17, The article number is 176.

König S, Lindwall M and Johansson B (2019) Involuntary and delayed retirement as a possible health risk for lower educated retirees. Journal of Population Ageing 12, 475-489.

Kooij DTAM, de Lange AH, Jansen PG, Kanfer R and Dikkers JS (2011) Age and work-related motives: results of a meta-analysis. Journal of Organizational Behavior 32, 197-225.

Ní Léime Á, Ogg J, Rašticová M, Street D, Krekula C, Bédiová M and Madero-Cabib I (eds) (2020) Extended Working Life Policies. International Gender and Health Perspectives. Cham, Switzerland: Springer.

Lichtenthaler PW and Fischbach A (2016) Job crafting and motivation to continue working beyond retirement age. Career Development International 21, 477-497.

Lowe GS (2007) 21st Century Job Quality: Achieving What Canadians Want. Ottawa: Canadian Policy Research Networks.

Nilsson K (2017) The influence of work environmental and motivation factors on seniors' attitudes to an extended working life or to retire. A cross sectional study with employees 55-74 years of age. Open Journal of Social Sciences 5, 30-41.

Organisation for Economic Co-operation and Development (OECD) (2019) Pensions at a Glance 2019: OECD and G20 Indicators. Paris: OECD Publishing.

Phillipson C (2019) 'Fuller'or 'extended' working lives? Critical perspectives on changing transitions from work to retirement. Ageing \& Society 39, 629-650.

Polat T, Bal PM and Jansen PG (2017) How do development HR practices contribute to employees' motivation to continue working beyond retirement age? Work, Aging and Retirement 3, 366-378.

Radl J (2012) Too old to work, or too young to retire? The pervasiveness of age norms in Western Europe. Work, Employment and Society 26, 755-771.

Scharn M, Sewdas R, Boot CRL, Huisman M, Lindeboom M and van der Beek AJ (2018) Domains and determinants of retirement timing: a systematic review of longitudinal studies. BMC Public Health 18, The article number is 1083 . 
Schreurs B, van Emmerik H, de Cuyper N, Notelaers G and de Witte H (2011) Job demands-resources and early retirement intention: differences between blue- and white-collar workers. Economic and Industrial Democracy 32, 47-68.

Schröder H, Kersting A, Gilberg R and Steinwede J (2013) Methodenbericht zur Haupterhebung lidA leben in der Arbeit [Method Report on the Main Survey of lidA - Living at Work] (FDZ Method Report 01/2013]. Nuremberg, Germany: Research Data Centre (FDZ) of the Germen Federal Employment Agency (BA) at the Institue of Employment Research (IAB).

Steinwede J, Kleudgen M, Häring A and Schröder H (2015) Methodenbericht zur Haupterhebung lidA leben in der Arbeit, 2. Welle [Method Report on the Main Survey of lidA - Living at Work, 2nd Wave] (FDZ Method Report 07/2015). Nuremberg, Germany: Research Data Centre (FDZ) of the Germen Federal Employment Agency (BA) at the Institue of Employment Research (IAB).

Steinwede J, Ruiz Marcos J and Kleudgen M (2018) Methodenbericht lidA Welle 3 [Method Report lidA Wave 3]. Bonn, Germany: infas Institute for Applied Social Sciences.

Taylor P, Loretto W, Marshall V, Earl C and Phillipson C (2016) The older worker: identifying a critical research agenda. Social Policy and Society 15, 675-689.

van Aerden K, Moors G, Levecque K and Vanroelen C (2015) The relationship between employment quality and work-related well-being in the European labor force. Journal of Vocational Behavior 86, 66-76.

Vanroelen C, Louckx F, Moors G and Levecque K (2010) The clustering of health-related occupational stressors among contemporary wage-earners. European Journal of Work and Organizational Psychology 19, 654-674.

Wang M and Shultz KS (2010) Employee retirement: a review and recommendations for future investigation. Journal of Management 36, 172-206.

Wong CM and Tetrick LE (2017) Job crafting: older workers' mechanism for maintaining person-job fit. Frontiers in Psychology 8, 1548.

Cite this article: Stiller M, Garthe N, Hasselhorn HM (2021). Job quality trajectories among baby-boomers in Germany and their consequences for the motivation to work - results from the lidA cohort study. Ageing \& Society 1-23. https://doi.org/10.1017/S0144686X21001343 